\title{
An online survey to study the relationship between patients' health literacy and coping style and their preferences for self-management-related information
}

This article was published in the following Dove Press journal:

Patient Preference and Adherence

6 May 2014

Number of times this article has been viewed

\author{
Sandra Vosbergen' \\ Niels Peek' \\ Johanna MR \\ Mulder-Wiggers' \\ Hareld MC Kemps ${ }^{1,2}$ \\ Roderik A Kraaijenhagen ${ }^{3}$ \\ Monique WM Jaspers ${ }^{1,4}$ \\ Joyca PW Lacroix ${ }^{5}$ \\ 'Department of Medical Informatics, \\ Academic Medical Center, Amsterdam, \\ the Netherlands, ${ }^{2}$ Department of \\ Cardiology, Máxima Medical Centre, \\ Veldhoven, the Netherlands, ${ }^{3}$ NIPED \\ Research Foundation, Amsterdam, \\ the Netherlands, ${ }^{4}$ Center for Human \\ Factors Engineering of Health \\ Information Technology (HIT Lab), \\ Academic Medical Center, Amsterdam, \\ the Netherlands, ${ }^{5}$ Department of \\ Brain, Body and Behavior, Philips \\ Research, Eindhoven, the Netherlands
}

Objective: To evaluate patients' preferences for message features and assess their relationships with health literacy, monitor-blunter coping style, and other patient-dependent characteristics. Methods: Patients with coronary heart disease completed an internet-based survey, which assessed health literacy and monitor-blunter coping style, as well as various other patient characteristics such as sociodemographics, disease history, and explicit information preferences. To assess preferences for message features, nine text sets differing in one of nine message features were composed, and participants were asked to state their preferences.

Results: The survey was completed by 213 patients. For three of the nine text sets, a relationship was found between patient preference and health literacy or monitor-blunter coping style. Patients with low health literacy preferred the text based on patient experience. Patients with a monitoring coping style preferred information on short-term effects of their treatment and mentioning of explicit risks. Various other patient characteristics such as marital status, social support, disease history, and age also showed a strong association.

Conclusion: Individual differences exist in patients' preferences for message features, and these preferences relate to patient characteristics such as health literacy and monitor-blunter coping style.

Keywords: patient preferences, patient education, monitor-blunter coping style, information tailoring, message features

\section{Introduction}

Educating patients about their medication and lifestyle behavior (eg, diet and exercise behavior) is an important aspect of the care provided to patients with a chronic disease. Together with health care providers, chronically ill patients - such as patients with coronary heart disease (CHD) - play an important role in the management of their disease because it requires them to adapt their lives to the limitations imposed by their illness, make changes to their lifestyle behavior, and follow a medication regimen. Often, health care providers use education to motivate and help patients to understand the need for such behavioral changes, which is a basic requirement for initiating those changes. Currently, most of the materials used to educate patients rely on a one-size-fits-all approach.

Previous research on patient education has shown that, compared with more generic messages, tailoring health communication to the characteristics of individual patients enhances the effectiveness of messages. ${ }^{1-11}$ While many of these studies focused on tailoring the content of health-related messages to patients' individual characteristics
Academic Medical Centre - University

of Amsterdam, Department of Medical Informatics, PO Box 22660, 1100 DD

Amsterdam, the Netherlands

Tel $+3 \mid 205667872$

Fax +31206919840

Email niels.peek@gmail.com 
(eg, sociodemographics), ${ }^{12,13}$ messages can also be tailored by altering the way in which generic content is formulated (eg, O’Keefe ${ }^{14,15}$ ). The aim of manipulating message formulations (in terms of their message style, structure, or content, hereafter referred to as "message features") is to make the message more salient to readers and to enhance the impact of the message on an individual's attitude or behavior. ${ }^{16}$ It has previously been shown that adapting certain message features can cause individuals to react differently to HIV disclosure, ${ }^{17}$ and can influence the perceived credibility of these messages (eg, Hong, ${ }^{18}$ Rains and $\mathrm{Karmikel}^{19}$ ). However, many of the studies that tailored messages by altering message features mainly focused on psychological constructs that have been shown to relate to how people perceive and process health messages (eg, need for cognition) rather than on patients' reported preferences for these message features..$^{2-4,7,8,12}$

Previous research has shown that matching information to patients' preferences can be beneficial for patients' anxiety and satisfaction with the way information is given. ${ }^{20,21}$ Therefore, researchers have suggested a need to tailor the type and amount of information to patients' preferences. ${ }^{22}$ Also, matching therapy conditions (ie, the role the therapist plays in the therapy, characteristics of the therapist, and type of intervention used) to patients' preferences has been shown to decrease dropout of therapy and to improve treatment outcomes in psychotherapy. ${ }^{23}$ In a previous qualitative study in which we explored the self-management experiences of $\mathrm{CHD}$ patients, we found an indication that these patients vary in their preferences for information provision. ${ }^{24}$ Patients expressed a desire for information that was not only tailored to their sociodemographic characteristics, health behavior, or information needs, but also to their preferences concerning information content, message complexity, and level of detail. ${ }^{24}$ Whether this variation also exists in a more general population of CHD patients and whether other patient characteristics influence these preferences is, however, to our knowledge, currently unknown.

Various patient characteristics might influence patients' preferences for message features. For example, two conditions that are assumed to be relevant are a patient's health literacy and monitor-blunter coping style. ${ }^{24}$ In the qualitative study mentioned previously, we found that some patients appeared to ignore complementary health information (eg, in instruction leaflets or on the internet) because they had difficulties understanding the medical terminology used, or because they perceived the information as threatening. ${ }^{24}$ The first finding might be explained by a patient's health literacy level and the second finding by a patient's monitor-blunter coping style.
Health literacy concerns the degree to which an individual has the capacity to obtain, process, and understand information needed to make health-related decisions. ${ }^{25}$ Monitor-blunter coping style describes how an individual copes with personally threatening information. ${ }^{26}$ Monitors look for cues in texts that may reduce their perceived health risks in order to alleviate their concerns and distress. ${ }^{27,28}$ Blunters tend to avoid information they find threatening, as this information will overwhelm them more easily than nonthreatening information. ${ }^{2,26}$ Health literacy has previously been shown to affect patients' understanding of diseases and their understanding of risk information. ${ }^{29,30}$ Previous studies have examined the effects of monitor-blunter coping style on various outcomes, including patients' satisfaction with health care, preferences for being informed, and healthy behavior. For example, it was shown that matching the amount of preparatory information to patients' coping style reduces the level of arousal in patients that are about to undergo a colonoscopy, ${ }^{31}$ and that patients with a monitoring coping style have a stronger desire to be informed than patients with a blunter coping style. ${ }^{32}$ Moreover, patients who are provided with messages that match their coping style are more likely to participate in screening and health promotion interventions. ${ }^{2,3}$ It is, however, unknown whether a person's health literacy level and coping style also play a role in explaining a preference for message features. It is, for example, unclear whether patients with a higher health literacy level prefer more difficult messages than those characterized by lower health literacy, or whether both patient groups would be satisfied with the less difficult message.

Various other patient characteristics, such as age, sex, education, health status, and family situation, have been shown to be related to patients' preferences for information giving and for involvement in decision-making in primary care. ${ }^{33}$ For example, higher educated patients gave greater preference to being told the truth than those with lower education. ${ }^{33}$ Also, Keller and Lehman found that the age and sex of patients influenced the message tactics required to achieve compliance with health recommendations. ${ }^{6}$ It is, however, unknown which patient characteristics influence patients' preferences for message features. An accurate identification of the characteristics that predict patients' preferences for message features would allow us to, in the future, improve the tailoring of health information to these characteristics.

\section{Objective}

In this study, we aimed to investigate 1) whether patients vary in their preferences for multiple message features, 
and 2) whether patients prefer messages that match their health literacy level and monitor-blunter coping style. Additionally, we aimed to explore whether other patient characteristics (sociodemographics, disease history, social support, health perception, physical status, current information needs, and explicit preferences with respect to sources and volume of medical information) contribute to patients' preferences. This study is intended as a first exploration of patients' preferences and the potential determinants of those preferences.

\section{Methods}

\section{Participants and study design}

A survey was distributed electronically via an online market research company (PanelClix, Amsterdam, the Netherlands) in May 2012. PanelClix is a branch of Euroclix, (Amsterdam, the Netherlands) which was founded in 1999 and certified by the International Organization of Standardization (ISO). The company has its own international online panel (with members in the Netherlands, Belgium, Germany, France, and the UK), consisting of more than 200,000 members in the Netherlands. Of those Dutch members, 2,528 had, at the time of this study, indicated having a heart problem or having experienced heart failure. Considering the exploratory nature of this study and the lack of data with which to conduct a power calculation, we chose a sample size that we expected to be sufficiently large for this initial exploration. For this study, we expected that the inclusion of approximately 200 people with CHD would be sufficient. To recruit these patients, PanelClix sent a request to people in their database (ie, people who had voluntarily signed up with them to take part in research) to join our survey. People were invited to participate in our study if they had previously indicated they had heart problems or had experienced heart failure and were 18 years or older.

In our survey, it was further assessed whether these people fit our particular inclusion criteria. People who reported they had or have had one or more of the following diseases or interventions were included: heart failure, angina pectoris, hypertension (medically treated), hyperlipidemia (medically treated), diabetes, cardiac arrhythmia (medically treated), acute myocardial infarction (AMI), unstable angina pectoris, coronary artery bypass grafting $(\mathrm{CABG})$, percutaneous coronary intervention (PCI), a pacemaker, or an implantable cardioverter defibrillator. Patients with congenital heart disease were excluded. People who completed the survey received a small incentive equivalent to 2 euros.
The Institutional Review Board of the Academic Medical Center, Amsterdam, the Netherlands, waived formal approval of the study.

\section{Survey}

The online survey comprised 31 questions divided into the following four sections: 1) sociodemographics, disease history, and information needs; 2) monitor-blunter coping style and health literacy; 3) respondents' explicit information preferences; and 4) respondents' preferred message features, using several sets of differently altered messages. Table 1 provides an overview of survey items from the first three sections.

Participants' monitor-blunter coping style was measured using an adapted version of the shortened Threatening Medical Situations Inventory (TMSI) ${ }^{32}$ The original shortened TMSI consists of two hypothetical cases that describe threatening medical situations. The first describes a case pertaining to "vague suspicious headache complaints"; the second pertains to "choosing for uncertain heart surgery". 34 Every hypothetical case is followed by a random order of three blunting and three monitoring questions, scored on a 5-point Likert scale from 1 to 5. The monitoring scale was shown to have a Cronbach's alpha of 0.77 and the blunting scale a Cronbach's alpha of $0.62 .{ }^{34}$ In this study, the shortened version of Ong et al's questionnaire ${ }^{34}$ was adapted by replacing the question concerning "choosing for uncertain heart surgery" with the question in the original TMSI about "acute appendicitis". ${ }^{35}$ This adaptation was made because our target group included heart patients and bias might therefore have been introduced due to the hypothetical nature of the questions. Thus, in total, the adapted shortened TMSI consisted of 12 items (six blunter and six monitoring items). The total score was calculated by subtracting the average of the blunter scores from the average of the monitor scores (range: -4 to +4 for this version of the scale; higher scores indicate a greater tendency toward a monitoring coping style).

Health literacy was measured using the Dutch version of the Set of Brief Screening Questions (D-SBSQ), dividing participants into low and high subjective health literacy. ${ }^{36}$ This questionnaire consists of three items, which are scored on a 5-point Likert scale from 0 to 4 . The total health literacy score is the average score. It has been shown that the D-SBSQ has a Cronbach's alpha of $0.69 .{ }^{36}$

To assess respondents' explicit preferences for the degree of detail they wish to receive about their disease and/or treatment, we used an adapted version of one of the items from the Cassileth Information Styles Questionnaire. ${ }^{37}$ Respondents 
Table I Descriptive statistics of survey completers who met study inclusion criteria $(\mathrm{N}=213)$

\begin{tabular}{|c|c|}
\hline Variable & Value \\
\hline \multicolumn{2}{|l|}{$\begin{array}{l}\text { Section I: sociodemographics, disease history, } \\
\text { and information needs }\end{array}$} \\
\hline Age, mean $\pm S D$ & $55.9 \pm 14.0$ \\
\hline Male sex & $138(64.8)$ \\
\hline \multicolumn{2}{|l|}{ Educational level } \\
\hline Low (elementary and lower secondary education) & $86(40.4)$ \\
\hline Intermediate (upper/postsecondary education) & $87(40.8)$ \\
\hline High (tertiary education) & $40(18.8)$ \\
\hline \multicolumn{2}{|l|}{ Marital status } \\
\hline Married or living together & $162(76.1)$ \\
\hline Single & $51(23.9)$ \\
\hline \multicolumn{2}{|l|}{ Work status } \\
\hline Paid or voluntary work & $83(39.0)$ \\
\hline On sick leave (under the Dutch Sickness Benefits Act) & $13(6.1)$ \\
\hline Retired or unemployed & $117(54.9)$ \\
\hline \multicolumn{2}{|l|}{ Health perception } \\
\hline Very good & $6(2.8)$ \\
\hline Good & $67(31.5)$ \\
\hline Neither good nor poor & $94(44.1)$ \\
\hline Poor & $42(19.7)$ \\
\hline Very poor & $4(1.9)$ \\
\hline \multicolumn{2}{|l|}{$\begin{array}{l}\text { Current or previous heart diseases and interventions } \\
\text { (multiple response options) }\end{array}$} \\
\hline Heart failure & $76(35.7)$ \\
\hline Angina pectoris & $90(42.3)$ \\
\hline Hypercholesterolemia and/or hypertension & $178(83.6)$ \\
\hline Diabetes & $54(25.4)$ \\
\hline Familial hypercholesterolemia & $50(23.5)$ \\
\hline Cardiac arrhythmia & II $5(54.0)$ \\
\hline AMI & $90(42.3)$ \\
\hline CABG & $30(14.1)$ \\
\hline $\mathrm{PCl}$ & $77(36.2)$ \\
\hline Pacemaker and/or ICD & $15(7.0)$ \\
\hline CABG or AMI less than I year ago & $22(10.3)$ \\
\hline $\mathrm{PCl}$ less than I year ago & $20(9.4)$ \\
\hline Influence of heart disease on life, mean \pm SD (range: $0-10$ ) & $6.1 \pm 2.7$ \\
\hline $\begin{array}{l}\text { Physical discomfort because of heart disease, mean } \pm \text { SD } \\
\text { (range: } 0-10 \text { ) }\end{array}$ & $5.4 \pm 2.6$ \\
\hline \multicolumn{2}{|l|}{ Availability of social support $(\mathrm{N}=2 \mid 2)$} \\
\hline Never & $2(0.9)$ \\
\hline Seldom & $16(7.5)$ \\
\hline Sometimes & $49(23.1)$ \\
\hline Often & $50(23.6)$ \\
\hline Always & $95(44.8)$ \\
\hline \multicolumn{2}{|l|}{$\begin{array}{l}\text { Availability of people who can give advice on a problem } \\
(\mathrm{N}=2 \mid 2)\end{array}$} \\
\hline Never & $10(4.7)$ \\
\hline Seldom & $17(8.0)$ \\
\hline Sometimes & $67(31.6)$ \\
\hline Often & $56(26.4)$ \\
\hline Always & $62(29.2)$ \\
\hline \multicolumn{2}{|l|}{$\begin{array}{l}\text { Categories with unanswered questions ( } \mathrm{N}=208) \\
\text { (multiple response options) }\end{array}$} \\
\hline The disease and its causes & $41(19.7)$ \\
\hline The progress of the disease and the prognosis & $50(24.0)$ \\
\hline
\end{tabular}

Table I (Continued)

\begin{tabular}{ll}
\hline Variable & Value \\
\hline Medication usage & $79(38.0)$ \\
Diet & $30(14.4)$ \\
Physical exercise & $43(20.7)$ \\
Smoking & $18(8.7)$ \\
Feelings and emotions & $45(21.6)$ \\
Alcohol consumption & $10(4.8)$ \\
Other or none & $52(25.0)$
\end{tabular}

Section 2: health literacy and monitor-blunter coping style

Total health literacy score, mean \pm SD (range: $0-4) \quad 3.2 \pm 0.6$

Need support with reading letters or leaflets, mean \pm SD $\quad 3.3 \pm 1.0$

Confidence filling in medical forms, mean $\pm S D \quad 3.1 \pm 0.8$

Understanding written information, mean \pm SD $\quad 3.1 \pm 0.9$

Monitor-blunter coping style score (range: -4 to +4 ),

mean \pm SD

$-0.3 \pm 0.9$

Blunter questions (range: $1-6$ ), mean $\pm S D \quad 3.1 \pm 0.8$

Monitor questions (range: I-6), mean \pm SD $\quad 2.9 \pm 0.7$

Section 3: respondents' explicit information

preferences

Explicit preferences with respect to information

on disease and treatment $(\mathrm{N}=2 \mathrm{I} / 0)$

I only want the information about my disease and

treatment that I need to take care of myself properly

I want additional information about my disease and

treatment, but only about the underlying mechanisms

of the disease

I want as much information as possible about my disease

and treatment, both about the underlying mechanisms

of the disease as well as the risks and side effects

Preferred source of information ( $\mathrm{N}=2 \mathrm{II})$

Scientific research

$56(26.5)$

Patient's experience 33 (15.6)

Physician's experience $122(57.8)$

Note: Unless stated otherwise, values represent number (percentage) of participants.

Abbreviations: N, number; SD, standard deviation; AMI, acute myocardial infarction; $C A B G$, coronary artery bypass grafting; $\mathrm{PCl}$, percutaneous coronary intervention; ICD, implantable cardioverter defibrillator.

were asked to indicate what they would like to know about their disease or treatment (see Table 1 for the response options). To assess the preferred source of information provided, respondents were asked to rank three sources (scientific, patient experiences, and physician experiences) from most preferred to least preferred.

The final section of the survey consisted of eight text pairs and one text trio, which were used to assess respondents' implicit preferences for message features. Per text set, participants were asked to indicate which text they preferred or whether they had "no preference". Every text set differed in one of the following message features: 1) language style; 2) level of abstractness; 3) actionability; 4) source of information; 5) temporal perspective (current or future situation); 
6) level of disease-specific information provided; 7) level of treatment-specific information provided; 8) explicitly threatening content; and 9) cues (positive or negative). The message features were derived from literature on health literacy and monitor-blunter coping style. . $^{2,3,38,39}$ We hypothesized that preferences for these message features would relate to health literacy and monitor-blunter coping style. Text sets 1 through 4 were based on the health literacy literature, and text sets 5 through 9 on the monitorblunter coping style literature. All text sets can be found in the Supplementary material, together with a more comprehensive description of how the text sets were developed.

\section{Data analysis}

Descriptive statistics were used to examine participant characteristics and their preferences for message features. Response bias was checked by comparing respondents who completed and who did not complete the survey by age and sex. Groups with different preferences for a particular message feature were compared with respect to health literacy and monitorblunter coping style using Student's $t$-test (two groups) or analysis of variance (three groups). This was first examined for all response options except for "no preference", and subsequently for "no preference" versus any other choice.

Assessment of whether the other participant variables were associated with preferences for message features was performed with logistic regression analysis. Because the limited size of our sample did not permit reliable estimation of a multivariable regression model with all the variables, we proceeded in two consecutive steps to arrive at the associated participant variables. First, for each message feature separately, all variables were analyzed with univariate logistic regression, adjusting for age and sex (ie, these variables were always present in the model). Second, all variables that were associated $(P<0.1)$ with a particular message feature in the univariate logistic regression analysis were included in the multivariable logistic regression analysis for that message feature. Again, age and sex were always included in the multivariable analyses. Ethnicity was not included in any of the analyses because there were only five respondents with a mother tongue other than Dutch. Initially, the regression analyses were performed for all response options except for "no preference"; participants who chose this option were excluded. Subsequently, the regression analyses were repeated for "no preference" versus any other choice. The preference for messages adapted to different sources of information consisted of three potential answer categories and was, therefore, in both the univariate and the multivariate regression analyses, examined by performing two separate analyses in which responses concerning one text preference were compared with the responses concerning the other two.

Based on descriptive statistics of the variables, five variables were categorized into fewer categories. Health perception was categorized into "good", "neither good nor poor", and "poor". Work status was categorized into "paid or voluntary work" and "on sick leave, retired, or unemployed". The two variables representing the availability of persons who can give support and advice were categorized into "no" and "yes". Finally, what respondents wanted to know about their disease or treatment was divided into "only a particular part of the available information" and "as much information as possible". To examine the relationship between having had a recent cardiac event or intervention and the preference for message features, two dichotomous variables were constructed: "whether a person had an AMI or CABG less than 1 year ago" and "whether a person had a PCI less than 1 year ago".

Data were analyzed using the Statistical Package for the Social Sciences ([SPSS] v 19.0; IBM Corporation, Armonk, NY, USA) and R software (v 2.13.1; The R Foundation for Statistical Computing, Vienna, Austria).

\section{Results}

\section{Participant characteristics}

In total, 273 out of 318 people who started the survey completed it (85.8\%). There were no differences in sex between participants who completed and who did not complete the questionnaire $(\mathrm{N}=45)$, but those who completed the questionnaire were significantly younger (mean age [standard deviation]: 55.9 years [14.0] versus 61.2 years [9.2]; $P=0.02$ ). Of these 273 participants, 60 (18.9\%) were excluded from the study later because they had a congenital heart disease $(\mathrm{N}=56)$ or did not seem to have any form of heart disease $(\mathrm{N}=4)$. As a result, a total of 213 participants were included in the analyses (67\%). Table 1 summarizes their results on the first three sections of the questionnaire (sociodemographic and other characteristics).

\section{Variation in implicit preferences for message features}

The second column in Table 2 shows respondents' preferences for the message features. Data showed that, for all text sets, the vast majority of the respondents (range 79.2\%-89.7\%) had a preference for one of the texts in the text set. Which text 
Table 2 Preference for message features and univariate analysis of the association between monitor-blunter coping style/health literacy and preference for message features

\begin{tabular}{|c|c|c|c|c|c|}
\hline \multirow[t]{2}{*}{ Text set } & \multirow[t]{2}{*}{$\begin{array}{l}\text { Respondents' preference for the message } \\
\text { feature }\end{array}$} & \multirow{2}{*}{$\begin{array}{l}\text { Participants } \\
\mathbf{N}(\%)\end{array}$} & \multirow{2}{*}{$\begin{array}{l}\text { Monitor-blunter } \\
\text { coping style }\end{array}$} & \multirow{2}{*}{$\begin{array}{l}\text { Health literacy } \\
\text { Mean } \pm \text { SD }\end{array}$} & \multirow[t]{2}{*}{$P$-value } \\
\hline & & & & & \\
\hline \multirow[t]{5}{*}{ I. } & Language style (N=208) & & & & \\
\hline & Layperson's language & $60(28.8)$ & & $3.08 \pm 0.676$ & \\
\hline & Medical language & $117(56.3)$ & & $3.22 \pm 0.554$ & 0.138 \\
\hline & Preference for this message feature & & & $3.17 \pm 0.600$ & \\
\hline & No preference for this message feature & $31(14.9)$ & & $3.09 \pm 0.672$ & 0.474 \\
\hline \multirow[t]{5}{*}{2.} & Level of abstractness $(\mathrm{N}=2 \mid 3)$ & & & & \\
\hline & Concrete recommendations & $128(60.1)$ & & $3.17 \pm 0.634$ & \\
\hline & Abstract recommendations & $53(24.9)$ & & $3.09 \pm 0.579$ & 0.459 \\
\hline & Preference for this message feature & & & $3.15 \pm 0.618$ & \\
\hline & No preference for this message feature & $32(15.0)$ & & $3.21 \pm 0.579$ & 0.604 \\
\hline \multirow[t]{5}{*}{3.} & Actionability $(\mathrm{N}=2 \mid 0)$ & & & & \\
\hline & Non-actionable recommendations & $43(20.5)$ & & $3.02 \pm 0.709$ & \\
\hline & Actionable recommendations & $143(68.1)$ & & $3.18 \pm 0.552$ & 0.103 \\
\hline & Preference for this message feature & & & $3.15 \pm 0.594$ & \\
\hline & No preference for this message feature & $24(11.4)$ & & $3.22 \pm 0.727$ & 0.561 \\
\hline \multirow[t]{6}{*}{4.} & Source of information $(\mathrm{N}=209)$ & & & & \\
\hline & Physician’s experience & $63(29.7)$ & & $3.19 \pm 0.652$ & \\
\hline & Patient's experience & $34(16.0)$ & & $2.83 \pm 0.653$ & \\
\hline & Scientific research & $71(33.5)$ & & $3.27 \pm 0.559$ & $0.003 *$ \\
\hline & Preference for this message feature & & & $3.15 \pm 0.633$ & \\
\hline & No preference for this message feature & $44(20.8)$ & & $3.16 \pm 0.521$ & 0.936 \\
\hline \multirow[t]{5}{*}{5.} & Temporal perspective $(\mathrm{N}=2 \mid 2)$ & & & & \\
\hline & Current & $86(40.6)$ & $-0.06 \pm 1.024$ & & \\
\hline & Future & $87(41.0)$ & $-0.37 \pm 0.824$ & & $0.029 *$ \\
\hline & Preference for this message feature & & $-0.22 \pm 0.939$ & & \\
\hline & No preference for this message feature & $39(18.4)$ & $-0.43 \pm 0.902$ & & 0.208 \\
\hline \multirow[t]{5}{*}{6.} & $\begin{array}{l}\text { Level of disease-specific information provided } \\
(\mathrm{N}=210)\end{array}$ & & & & \\
\hline & Concise information & $35(16.7)$ & $-0.35 \pm 1.077$ & & \\
\hline & Detailed information & $146(69.5)$ & $-0.21 \pm 0.920$ & & 0.444 \\
\hline & Preference for this message feature & & $-0.24 \pm 0.951$ & & \\
\hline & No preference for this message feature & $29(13.8)$ & $-0.4 I \pm 0.755$ & & 0.340 \\
\hline \multirow[t]{5}{*}{7.} & $\begin{array}{l}\text { Level of treatment-specific information provided } \\
(\mathrm{N}=2 \mathrm{II})\end{array}$ & & & & \\
\hline & Concise information & $30(14.2)$ & $-0.35 \pm 1.076$ & & \\
\hline & Detailed information & I5I (7I.6) & $-0.20 \pm 0.935$ & & $0.44 I$ \\
\hline & Preference for this message feature & & $-0.23 \pm 0.959$ & & \\
\hline & No preference for this message feature & $30(14.2)$ & $-0.43 \pm 0.756$ & & 0.259 \\
\hline \multirow[t]{5}{*}{8.} & Explicitly threatening content $(\mathrm{N}=2 \mid 3)$ & & & & \\
\hline & $\begin{array}{l}\text { Information that includes explicit risks } \\
\text { and side effects }\end{array}$ & II 8 (55.4) & $-0.11 \pm 0.949$ & & \\
\hline & $\begin{array}{l}\text { Information that excludes explicit risks } \\
\text { and side effects }\end{array}$ & $73(34.3)$ & $-0.5 \mid \pm 0.922$ & & $0.005^{*}$ \\
\hline & Preference for this message feature & & $-0.27 \pm 0.956$ & & \\
\hline & No preference for this message feature & $22(10.3)$ & $-0.24 \pm 0.734$ & & 0.914 \\
\hline \multirow[t]{5}{*}{9.} & Cues (positive or negative) $(\mathrm{N}=2 \mid 2)$ & & & & \\
\hline & Risks reduced by physical exercise & $58(27.4)$ & $-0.24 \pm 0.910$ & & \\
\hline & Benefits of physical exercise & $119(56.1)$ & $-0.22 \pm 0.969$ & & 0.903 \\
\hline & Preference for this message feature & & $-0.23 \pm 0.947$ & & \\
\hline & No preference for this message feature & $35(16.5)$ & $-0.46 \pm 0.865$ & & 0.183 \\
\hline
\end{tabular}

Notes: Preference for text sets I-4 were hypothesized to be related to health literacy, and text sets 5-9 were hypothesized to be related to monitor-blunter coping style. Higher monitor-blunter coping style scores mean a greater tendency toward a monitoring coping style (range -4 to +4$)$. Higher health literacy scores mean higher health literacy (range $\mathrm{I}-5)$. $* \mathrm{P}<0.05$.

Abbreviations: N, number; SD, standard deviation. 
they preferred per text set varied between patients; they most often had a preference for treatment-specific and diseasespecific detailed information $(71.6 \%$ and $69.5 \%$ of the respondents, respectively), while their preferences for the temporal perspective varied most $(40.6 \%$ of the respondents preferred a current temporal perspective whereas $41.0 \%$ of the respondents preferred a future temporal perspective). For all the other text sets, the range for the least chosen message feature was between $20.5 \%$ for non-actionable advice and $34.3 \%$ for information that excludes explicit risks and side effects.

\section{Relation with patients' health literacy and monitor-blunter coping style}

Table 2 also shows the results of the univariate analyses of participants' preferences for message features in relation to either their health literacy level or monitor-blunter coping style. Whether patients preferred a particular message feature or had no preference was not related to health literacy or monitor-blunter coping style in any of the nine text sets. Furthermore, participants' preferences for message features were not related to their health literacy level, except for preferences that varied with regard to the information source. Participants who preferred the messages based on scientific research or a physician's experience had higher health literacy than those who preferred the message based on a patient's experiences.

Participants' preferences for message features were related to monitor-blunter coping style for two of the message features: temporal perspective and explicitly threatening content. Participants who preferred the message that described the current effects of medication tended more towards a blunting coping style than those who preferred the message that described future effects. Participants who preferred the message that included the risks and side effects of medication showed a greater tendency toward a monitoring coping style than those who preferred the message without such risks and side effects.

\section{Exploration of other patient characteristics associated with preferences for message features}

After adjusting for age and sex, few participant characteristics remained that were associated with whether participants had a preference for message features. First, respondents who explicitly indicated that they did not want to know everything about their disease and treatment were less likely (odds ratio [OR] [95\% confidence interval $\{\mathrm{CI}\}]$ : $0.30[0.13-0.68])$ to have a preference for little or detailed disease-specific information $(P=0.004)$. Second, respondents who indicated they had less social support than others were less likely (OR [95\% CI]: 0.39 [0.19-0.78]) to care about the source of information $(P=0.008)$. Finally, respondents who had not undergone an AMI or CABG less than 1 year ago, or who did not have an AMI or CABG at all, did have a preference with respect to the actionability of messages $(P=0.005)$.

Table 3 shows the results of the multivariate logistic regression analysis for the nine text sets. Per message feature, the number of patient characteristics that were associated with this message feature varied from zero to three. None of the participant characteristics assessed in the survey were significantly related to the preference for cues (positive or negative) given in messages. The explicit preference for little or detailed information about the disease and treatment was associated with the greatest number of message features (four), followed by age (three). The strongest associations were found for the following characteristics: having had a PCI more than 1 year ago or not having had a PCI (OR: 3.77), educational level (OR: 3.41), explicit preference for little or detailed information about the disease and treatment (OR: 3.20), marital status (OR: 3.01), and health literacy (OR: 3.00$)$.

\section{Discussion \\ Main findings}

In this study, we found individual differences among CHD patients in their preferences for message features that can be used in self-management-related information, and these preferences were related to health literacy level and monitor-blunter coping style. Participants with low health literacy were more likely to prefer information based on other patients' experiences. Participants with a blunting coping style were more likely to prefer messages that described what they can expect from their treatment in the future rather than the immediate consequences. Furthermore, in line with their blunting coping style, they were found to be more likely to prefer information that did not mention explicit risks and side effects of their treatment. However, although the direction of the associations in the multivariate analyses of these message features was in line with these results, these associations were not significant.

Furthermore, we observed that preferences for message features were associated with several patient characteristics. Sociodemographic factors related to preferences were age, marital status, educational level, and availability of social support and someone who can give advice, but not 
Table 3 Multivariate analysis of all patient characteristics per text set that were associated $(P<0.1)$ with preferences for that text set in the univariate analysis

\begin{tabular}{|c|c|c|}
\hline Text pair or trio & Variable & OR $(95 \% \mathrm{CI})$ \\
\hline \multicolumn{3}{|c|}{ Medical language $(\mathrm{N}=177)$} \\
\hline & Female sex & $1.24(0.6 \mathrm{I}-2.53)$ \\
\hline & Higher age (per 10 years) & $1.17(0.92-1.49)$ \\
\hline & High educational level & Reference category \\
\hline & Low educational level & $0.30(0.09-0.99)^{*}$ \\
\hline & Intermediate educational level & $0.29(0.09-0.94)^{*}$ \\
\hline & Having a pacemaker and/or ICD & $0.38(0.1 \mathrm{I}-1.3 \mathrm{I})$ \\
\hline & Having someone who can give support & $2.10(1.02-4.31)^{*}$ \\
\hline \multicolumn{3}{|c|}{ High level of abstractness $(\mathrm{N}=179)$} \\
\hline & Female sex & $1.08(0.53-2.20)$ \\
\hline & Higher age (per 10 years) & $1.41(1.07-1.84)^{*}$ \\
\hline & Explicit preference for little information about & $1.99(0.97-4.08)$ \\
\hline & disease and treatment & \\
\hline \multicolumn{3}{|c|}{ Highly actionable message $(\mathrm{N}=184)$} \\
\hline & Female sex & $1.38(0.63-3.05)$ \\
\hline & Lower age (per 10 years) & $1.01(0.78-1.30)$ \\
\hline & Having had an AMI & $1.98(0.84-4.67)$ \\
\hline & Having had a $\mathrm{PCl}$ & $1.45(0.59-3.53)$ \\
\hline & Explicit preference for detailed information & $3.21(1.53-6.7 I)^{*}$ \\
\hline & about disease and treatment & \\
\hline \multicolumn{3}{|c|}{ Source of information - patient's experience versus physician's experience or scientific research $(\mathrm{N}=164)$} \\
\hline & Higher age (per 10 years) & $1.10(0.80-1.51)$ \\
\hline & Female sex & $1.91(0.72-5.12)$ \\
\hline & Information source: scientific research & Reference category \\
\hline & Information source: physician's experience & $0.49(0.16-1.48)$ \\
\hline & Information source: patient's experience & $1.42(0.42-4.80)$ \\
\hline & Lower health literacy (range: $0-4$ ) & $3.00(1.45-6.21)^{*}$ \\
\hline & Higher number of categories with unanswered & $1.56(1.15-2.12)^{*}$ \\
\hline & questions & \\
\hline & Having diabetes & $0.35(0.09-1.42)$ \\
\hline & Having cardiac arrhythmia & $0.39(0.14-0.96)^{*}$ \\
\hline & Explicit preference for little information about & $1.70(0.64-4.5 \mathrm{I})$ \\
\hline & disease and treatment & \\
\hline \multicolumn{3}{|c|}{ Source of information - scientific research versus patient's or physician's experience ( $N=168)$} \\
\hline & Lower age (per 10 years) & $1.10(0.87-1.40)$ \\
\hline & Male sex & $1.48(0.72-3.04)$ \\
\hline & Being single & $2.19(1.00-4.76)^{*}$ \\
\hline & High health literacy (range: 0-4) & $1.89(1.07-3.35)$ \\
\hline & Having heart failure & $1.98(1.01-3.88)^{*}$ \\
\hline & No AMI or CABG less than I year ago, or no & $2.10(0.67-6.58)$ \\
\hline & AMI or CABG at all & \\
\hline \multicolumn{3}{|c|}{ Future temporal perspective $(\mathrm{N}=172)$} \\
\hline & Female sex & $1.01(0.50-2.03)$ \\
\hline & Higher age (per 10 years) & $1.02(0.8 \mathrm{I}-\mathrm{I} .30)$ \\
\hline & A more blunting coping style (range: -4 to +4 ) & $1.42(0.99-2.05)$ \\
\hline & Being single & $3.01(1.30-6.99)^{*}$ \\
\hline & Having diabetes & $0.52(0.25-1.09)$ \\
\hline & Having someone who can give advice & $2.15(1.08-4.26)^{*}$ \\
\hline \multicolumn{3}{|c|}{ High level of disease-specific information provided $(\mathrm{N}=178)$} \\
\hline & Female sex & I.II (0.47-2.63) \\
\hline & Higher age (per 10 years) & $1.07(0.80-1.43)$ \\
\hline & Married or living together & $2.22(0.93-5.32)$ \\
\hline & Having diabetes & $2.70(0.84-8.62)$ \\
\hline & Explicit preference for detailed information & $2.89(|.30-6.4|)^{*}$ \\
\hline & about disease and treatment & \\
\hline
\end{tabular}


Table 3 (Continued)

\begin{tabular}{|c|c|c|}
\hline Text pair or trio & Variable & OR $(95 \% \mathrm{CI})$ \\
\hline \multicolumn{3}{|c|}{ High level of treatment-specific information provided $(\mathrm{N}=179)$} \\
\hline & Female sex & $1.94(0.79-4.72)$ \\
\hline & Lower age (per 10 years) & $1.62(1.11-2.35)^{*}$ \\
\hline & Having had a PCl more than I year ago or not & $3.77(1.13-12.52)^{*}$ \\
\hline & having had a $\mathrm{PCl}$ & \\
\hline & Explicit preference for detailed information & $3.03(1.29-7.14)^{*}$ \\
\hline & about disease and treatment & \\
\hline \multicolumn{3}{|c|}{ Nonthreatening information ( $\mathrm{N}=188)$} \\
\hline & Female sex & $1.20(0.60-2.38)$ \\
\hline & Higher age (per 10 years) & $1.51(1.16-1.97)^{*}$ \\
\hline & A more blunting coping style (range: -4 to +4 ) & $1.35(0.92-1.98)$ \\
\hline & Lower health literacy (range: $0-4$ ) & $1.95(1.11-3.44)^{*}$ \\
\hline & Explicit preference for little information about & $2.65(1.28-5.48)^{*}$ \\
\hline & disease and treatment & \\
\hline \multicolumn{3}{|c|}{ Positive cues $(\mathrm{N}=177)$} \\
\hline & Female sex & $1.53(0.74-3.19)$ \\
\hline & Lower age (per 10 years) & $1.26(0.98-1.63)$ \\
\hline & Higher health literacy (range: 0-4) & $1.4 \mathrm{I}(0.79-2.50)$ \\
\hline & Medical history of cardiac arrhythmia & $0.5 I(0.26-1.02)$ \\
\hline & Poor health perception & Reference category \\
\hline & Good health perception & $2.22(0.87-5.70)$ \\
\hline & Intermediate health perception & $0.86(0.38-1.97)$ \\
\hline
\end{tabular}

Note: $* P<0.05$.

Abbreviations: $\mathrm{N}$, number; OR, odds ratio; $\mathrm{Cl}$, confidence interval; ICD, implantable cardioverter defibrillator; AMI, acute myocardial infarction; PCl, percutaneous coronary intervention; $\mathrm{CABG}$, coronary artery bypass grafting.

the participant's sex. Of the disease-related factors, having a symptomatic heart disease (ie, heart failure, cardiac arrhythmia) turned out to be related to preferences for message features in particular, to the apparent source of information. Finally, participants' explicit preferences for degree of detail, their health literacy level, and the number of health-related topics for which they had unanswered questions were related to their preferences for message features. Both the number and nature of characteristics that were related to particular preferences varied greatly among the message features. No characteristics were found that were associated with preferences for message cues (positive or negative). Finally, participants' explicitly stated preference for degree of detail was related to their implicit preferences concerning four of the message features (actionability, level of disease- and treatment-specific details provided, and explicitly threatening content), which was made apparent by their choices for various sample texts.

\section{Relationship to other studies}

To our knowledge, no previous studies have investigated patients' preferences for message features that can be used in educational information or the patient characteristics associated with these preferences. Yet there have been studies investigating cancer patients' preferences for communication of prognostic communication. ${ }^{40}$ The review of Innes and Payne concludes that the only unanimous theme among the studies reviewed was that individualized assessment of patients' preferences for prognostic discussions is essential. ${ }^{40}$ They add that such preferences cannot simply be derived from identified trends for prognostic preferences by age, sex, culture, or disease stage, but that these preferences are more complex and are related to people's individual preferences. Our findings support this conclusion, as they show that individual differences between preferences for message features cannot be explained by individual differences in the sociodemographic and disease-related variables. Innes and Payne further illustrate that, based on the differences in patients' preferences and in how they cope with information, professionals appear to be faced with the following dilemma. ${ }^{40}$ While they have to provide all information necessary to create awareness, they should also respect the different reactions of patients on the amount of information given and the way in which it is disclosed. ${ }^{40}$ As appears from our study, similar problems seem to apply when educating patients with CHD. Many participants preferred not to receive all of the information. They preferred to have the threatening content excluded, and not to receive all of the details about their disease and/ or treatment. Consenting to these preferences will likely lead to higher satisfaction of the recipients of information, but it 
becomes more difficult to make them aware of the risks of unhealthy behavior.

There is also a growing body of literature on persuasive communication, coming from various domains including advertising, marketing, psychology, and communication. In a review on the persuasive impact of various components of language, Hosman describes how such things as positively versus negatively worded statements, active versus passive structures, and simple versus complex syntax increased the persuasive impact (ie, were either easier to comprehend or recall or were evaluated more positively). ${ }^{41}$ Although this suggests that messages composed in this way would be more persuasive, Hosman did not study the effect of variations in preferences for these message features. ${ }^{41}$ In our study, we found that some participants had other preferences for these message features. This suggests that these variations should be taken into account and that, by doing so, the effects of persuasiveness might be even greater. Additionally, in the literature, Hosman found mixed effects for those messages that are easier to visualize for receivers, such as messages that use more concrete wording. ${ }^{41}$ These different findings might be explained by the variation in the preferences for this message feature (ie, level of abstractness) found in this study.

\section{Strengths and limitations}

To our knowledge, this study is the first to explore patients' preferences for message features. We assessed a large set of information-processing, sociodemographic, and diseaserelated characteristics to gain an understanding of their relationship to patients' preferences for message features. To our knowledge, this is also the first study to explore these characteristics. Further, some studies include multiple message features simultaneously in their tailoring approaches (eg, Brug et $\mathrm{al}^{42}$ and Lutz et $\mathrm{al}^{43}$ ), which makes it difficult to gain insight into the individual characteristics contributing to certain preferences or intended behavior. In this study, we used one message feature at a time to distinguish the influencing variables.

The study has several limitations. First, our sample might be subject to selection bias. Patients who take part voluntarily in studies done by online market research companies might differ from the general CHD patient population in certain characteristics. Patients who have highly demanding jobs, are less familiar with the internet, have lower health literacy, or tend to avoid information that is threatening to them (blunters) might be less inclined to participate. Also, response bias analysis showed that participants were younger than dropouts.
Second, some of the data were missing, as we deliberately did not require participants to answer all of the questions. Also, we added the option "no preference" as an answer category, because varying features for which respondents are indifferent (ie, have no preference) will be useless. Although both of these choices might have influenced our data, the amount of missing data in our dataset used in the multivariate analyses always stayed below $10 \%$ and the dataset had a maximum of two missing answers per participant.

Third, our sample size was limited for the number of variables studied and, consequently, may have resulted in insufficient statistical power. Therefore, it was chosen to exclude all variables with $P<0.1$ from the multivariate analyses; because of this, we might, however, have missed particular factors. Having insufficient statistical power might also explain why, although we found that monitor-blunter coping style was related to patients' preferences for some message features, monitor-blunter coping style was not found to be associated with participants' preferences in the multivariate analysis. However, another patient characteristic might have explained all of the variance and our aim was not to confirm but to explore the potential determinants associated with patients' preferences.

Fourth, in this study, an adapted version of the shortened TMSI was used. ${ }^{34}$ Although the original TMSI and the shortened TMSI were both validated and showed acceptable internal consistency and the monitoring and blunting scales were found to be unrelated to each other, ${ }^{34,35}$ the adapted version was not validated. Fifth, the design of this study was limited by the fact that we did not randomize or vary the order of our text sets or of the message features. Finally, some caution must be exercised in generalizing the results to other patient groups or types of health care messages, as our study focused particularly on patients with CHD and messages related to self-management.

\section{Conclusion}

Individual differences were found among CHD patients in their preferences for message features, with the greatest variation in their preferences for temporal perspective, source of information, and inclusion or exclusion of explicitly threatening content. In general, most participants furthermore preferred messages that were actionable, concrete and detailed, and in medical language, and which contained positive cues. Although health literacy level and monitor-blunter coping style accounted for some of the variation in these preferences, other characteristics such as marital status, social support, disease history, age, and the explicit preferences for degree 
of detail were more strongly associated with these preferences. All the characteristics that were described here are readily available or can be assessed easily and quickly in clinical settings.

\section{Practice implications and future research}

Our findings suggest that patients' preferences for message features are important to consider when developing patient education materials. However, the variety in our findings makes it difficult to tailor each educational message to all relevant patient characteristics and preferences for message features. When there is no time or capacity to tailor messages at all, we recommend that messages be actionable, concrete and detailed, stated in medical language, and contain positive cues. When there is little time or capacity to tailor messages, we recommend taking account of those message features that vary the most between patients, such as the temporal perspective, source of information, and inclusion or exclusion of explicitly threatening content. Important patient factors that relate to these message features are age, marital status, disease history, availability of social support, level of health literacy, and explicit preferences for degree of detail. When there is ample capacity to tailor messages, we recommend also taking the other message features described in this study into account.

A major challenge for future research is to develop practicable strategies for eliciting and applying all preferences for message features of individual patients when educating them. The variation in preferences found in this study leads to a combinatorial problem and a potentially laborious, manual process of tailoring of all educational messages for individuals. In a follow-up study, we will investigate strategies to reduce the tailoring burden while still covering the individual differences in preferences for message features.

\section{Acknowledgments}

We would like to thank our survey respondents for their participation. We would also like to thank the Royal Dutch Pharmacists Association for their feedback on the texts developed. This study was funded by The Netherlands Organization for Health Research and Development (ZonMw), Disease Management Program for the Chronically III, under project number 300020008 . This organization was not involved in this study in any way other than providing financial support.

\section{Disclosure}

The authors report no conflicts of interest in this work.

\section{References}

1. Kreuter MW, Oswald DL, Bull FC, Clark EM. Are tailored health education materials always more effective than non-tailored materials? Health Educ Res. 2000;15(3):305-315.

2. Williams-Piehota P, Pizarro J, Schneider TR, Mowad L, Salovey P. Matching health messages to monitor-blunter coping styles to motivate screening mammography. Health Psychol. 2005;24(1):58-67.

3. Latimer AE, Katulak NA, Mowad L, Salovey P. Motivating cancer prevention and early detection behaviors using psychologically tailored messages. J Health Commun. 2005;10 Suppl 1:137-155.

4. Apanovitch AM, McCarthy D, Salovey P. Using message framing to motivate HIV testing among low-income, ethnic minority women. Health Psychol. 2003;22(1):60-67.

5. Gallagher KM, Updegraff JA. Health message framing effects on attitudes, intentions, and behavior: a meta-analytic review. Ann Behav Med. 2012;43(1):101-116.

6. Keller PA, Lehmann DR. Designing effective health communications: a meta-analysis. Journal of Public Policy Marketing. 2008;27(2): $117-130$.

7. O'Keefe DJ, Jensen JD. The relative persuasiveness of gain-framed and loss-framed messages for encouraging disease prevention behaviors: a meta-analytic review. J Health Commun. 2007;12(7): 623-644.

8. Noar SM, Benac CN, Harris MS. Does tailoring matter? Meta-analytic review of tailored print health behavior change interventions. Psychol Bull. 2007;133(4):673-693.

9. Sohl SJ, Moyer A. Tailored interventions to promote mammography screening: a meta-analytic review. Prev Med. 2007;45(4): 252-261.

10. Noar SM, Harrington NG, Van Stee SK, Aldrich RS. Tailored health communication to change lifestyle behaviors. Am J Lifestyle Med. 2011;5(2):112-122.

11. Lustria ML, Noar SM, Cortese J, Van Stee SK, Glueckauf RL, Lee J. A meta-analysis of web-delivered tailored health behavior change interventions. J Health Commun. 2013;18(9):1039-1069.

12. Noar SM, Harrington NG, Aldrich RS. The role of message tailoring in the development of persuasive health communication messages. In: Beck CS, editor. Communication Yearbook 33. New York, NY: Routledge; 2009:73-133.

13. Rimer BK, Kreuter MW. Advancing tailored health communication: a persuasion and message effects perspective. J Commun. 2006;56(s1):S184-S201.

14. O'Keefe DJ. The relative persuasiveness of different message types does not vary as a function of the persuasive outcome assessed: evidence from 29 meta-analyses of 2,062 effect sizes for 13 message variations. In: Cohen EL, editor. Communication Yearbook 37. New York, NY: Routledge; 2013:221-251.

15. O'Keefe DJ. Persuasive effects of strategic maneuvering. In: van Eemeren FH, editor. Examining Argumentation in Context: Fifteen Studies on Strategic Maneuvering. Amsterdam: John Benjamins Publishing Co.; 2009:285-296.

16. Dillard JP, Pfau M, editors. Introduction. In: The Persuasion Handbook: Developments in Theory and Practice. Thousand Oaks, CA: SAGE Publications; 2002:ix-ixi.

17. Caughlin JP, Bute JJ, Donovan-Kicken E, Kosenko KA, Ramey ME, Brashers DE. Do message features influence reactions to HIV disclosures? a multiple-goals perspective. Health Commun. 2009;24(3): 270-283.

18. Hong T. The influence of structural and message features on Web site credibility. J Am Soc Inf Sci Technol. 2006;57(1):114-127.

19. Rains SA, Karmikel CD. Health information-seeking and perceptions of website credibility: examining Web-use orientation, message characteristics, and structural features of websites. Comput Human Behav. 2009;25(2):544-553.

20. Ludwick-Rosenthal R, Neufeld RW. Preparation for undergoing an invasive medical procedure: interacting effects of information and coping style. J Consult Clin Psychol. 1993;61(1):156-164. 
21. Murtagh FE, Thorns A. Evaluation and ethical review of a tool to explore patient preferences for information and involvement in decision making. J Med Ethics. 2006;32(6):311-315.

22. Kiesler DJ, Auerbach SM. Optimal matches of patient preferences for information, decision-making and interpersonal behavior: evidence, models and interventions. Patient Educ Couns. 2006;61(3): 319-341.

23. Swift JK, Callahan JL, Vollmer BM. Preferences. J Clin Psychol. 2011; 67(2):155-165.

24. Vosbergen S, Janzen J, Stappers PJ, et al. A qualitative participatory study to identify experiences of coronary heart disease patients to support the development of online self-management services. Int J Med Inform. 2013;82(12):1183-1194.

25. Ratzan SC, Parker RM. Introduction. In: Selden CR, Zorn M, Ratzan SC, Parker RM, editors. National Library of Medicine Current Bibliographies in Medicine: Health Literacy. (NLM Pub. No. CBM 2000-1). Bethesda, MD: National Institutes of Health, U.S. Department of Health and Human Services; 2000.

26. Miller SM. Monitoring and blunting: validation of a questionnaire to assess styles of information seeking under threat. J Pers Soc Psychol. 1987;52(2):345-353.

27. Miller SM, Leinbach A, Brody DS. Coping style in hypertensive patients: nature and consequences. J Consult Clin Psychol. 1989;57(3):333-337.

28. Miller SM. The interacting effects of coping styles and situational variables in gynecologic settings: implications for research and treatment. J Psychosom Obst Gynaecol. 1988;9(1):23-34.

29. Giuse NB, Koonce TY, Storrow AB, Kusnoor SV, Ye F. Using health literacy and learning style preferences to optimize the delivery of health information. J Health Commun. 2012;17 Suppl 3:122-140.

30. Tait AR, Voepel-Lewis T, Brennan-Martinez C, McGonegal M, Levine R. Using animated computer-generated text and graphics to depict the risks and benefits of medical treatment. Am J Med. 2012;125(11):1103-1110.

31. Miller SM, Mangan CE. Interacting effects of information and coping style in adapting to gynecologic stress: should the doctor tell all? J Pers Soc Psychol. 1993;45:233-236.

32. Janssen NB, Oort FJ, Fockens P, Willems DL, de Haes HC, Smets EM. Under what conditions do patients want to be informed about their risk of a complication? A vignette study. J Med Ethics. 2009;35(5):276-282.
33. Jung HP, Baerveldt C, Olesen F, Grol R, Wensing M. Patient characteristics as predictors of primary health care preferences: a systematic literature analysis. Health Expect. 2003;6(2):160-181.

34. Ong LM, Visser MR, van Zuuren FJ, Rietbroek RC, Lammes FB, de Haes JC. Cancer patients' coping styles and doctor-patient communication. Psychooncology. 1999;8(2):155-166.

35. Van Zuuren FJ, De Groot KI, Mulder NL, Muris P. Coping with medical threat: an evaluation of the Threatening Medical Situations Inventory (TMSI). Pers Individ Diff. 1996;21(1):21-31.

36. Fransen MP, Van Schaik TM, Twickler TB, Essink-Bot ML. Applicability of internationally available health literacy measures in the Netherlands. J Health Commun. 2011;16 Suppl 3:134-149.

37. Cassileth BR, Zupkis RV, Sutton-Smith K, March V. Information and participation preferences among cancer patients. Ann Intern Med. 1980;92(6):832-836.

38. Health Literacy Online: A Guide to Writing and Designing Easy-ToUse Health Web Sites. 1st ed. Washington, DC: U.S. Department of Health and Human Services, Office of Disease Prevention and Health Promotion; 2010.

39. Williams-Piehota P, Schneider TR, Pizarro J, Mowad L, Salovey P. Matching health messages to information-processing styles: need for cognition and mammography utilization. Health Commun. 2003; 15(4):375-392.

40. Innes S, Payne S. Advanced cancer patients' prognostic information preferences: a review. Palliat Med. 2009;23(1):29-39.

41. Hosman LA. Language and persuasion. In: Dillard JP, Pfau M, editors. The Persuasion Handbook: Developments in Theory and Practice. Thousand Oaks: SAGE; 2002:371-390.

42. Brug J, Steenhuis I, van Assema P, de Vries H. The impact of a computer-tailored nutrition intervention. Prev Med. 1996;25(3): 236-242.

43. Lutz SF, Ammerman AS, Atwood JR, Campbell MK, DeVellis RF, Rosamond WD. Innovative newsletter interventions improve fruit and vegetable consumption in healthy adults. $J$ Am Diet Assoc. 1999;99(6):705-709.
Patient Preference and Adherence

\section{Publish your work in this journal}

Patient Preference and Adherence is an international, peer-reviewed, open access journal that focusing on the growing importance of patient preference and adherence throughout the therapeutic continuum. Patient satisfaction, acceptability, quality of life, compliance, persistence and their role in developing new therapeutic modalities and compounds to optimize

\section{Dovepress}

clinical outcomes for existing disease states are major areas of interest for the journal. This journal has been accepted for indexing on PubMed Central. The manuscript management system is completely online and includes a very quick and fair peer-review system, which is all easy to use. Visit http://www dovepress.com/testimonials.php to read real quotes from published authors. 